\title{
Combination of hyaluronic acid, carmellose, and osmoprotectants for the treatment of dry eye disease
}

This article was published in the following Dove Press journal:

Clinical Ophthalmology

\author{
Antonio José Mateo Orobia' \\ Jorge $\mathrm{Saa}^{2}$ \\ Alberto Ollero Lorenzo ${ }^{3}$ \\ José María Herreras ${ }^{4,5}$ \\ 'Cornea and Ocular Surface Unit, \\ Aragón Healthcare Research \\ Institute (Instituto de Investigación \\ Sanitaria de Aragón), Miguel Servet \\ University Hospital, Zaragoza, Spain; \\ ${ }^{2}$ Ophthalmology Department and \\ Research Unit of Jove Hospital \\ Foundation, Gijón, Spain; ${ }^{3}$ Cornea \\ and Ocular Surface Unit, Meixoeiro \\ Hospital, Complejo Hospitalario \\ Universitario de Vigo (CHUVI), Vigo, \\ Spain; ${ }^{4}$ Valladolid University Clinical \\ Hospital, Valladolid, Spain; ${ }^{5}$ University \\ Institute of Applied Ophthalmobiology \\ (IOBA [Instituto Universitario de \\ Oftalmobiología Aplicada]). Miguel \\ Delibes Campus, Paseo de Belén, \\ Valladolid, Spain
}

Background: Dry Eye Disease (DED) is a multifactorial disease, with a high prevalence, that can have a great impact on the quality of life of patients. The first step of treatment includes the use of lacrimal substitutes composed of polymers, possible to associate osmoprotectant agents to the lacrimal substitutes. The aim of this article is to analyze the properties of the combination of hyaluronic acid (HA), carmellose, and osmoprotectors (Optava Fusion ${ }^{\circledR}$; Allergan, Inc., Irvine, CA, USA) on DED. General considerations on the use of artificial tears are also proposed.

Methods: A group of ophthalmologists, experts in the management of the ocular surface, analyzed different aspects related to DED; among them, the use of artificial tears in general and the properties of the combination of HA, carmellose, and osmoprotectors, in particular, were discussed. A review of the literature was carried out, which included different articles published in Spanish, English, and French until April 2017.

Conclusions: DED is a common chronic pathology that usually requires sustained treatment. In addition, the combination of HA, carmellose, and osmoprotectors has proven to be effective in the treatment of symptoms and signs of dry eye by the synergistic action of all its components. This review provides key elements to help ophthalmologists who begin in the management of DED.

Keywords: dry eye disease, artificial tears, hyperosmolarity, osmoprotectants, hyaluronic acid, carmellose

\section{Introduction}

Dry Eye Disease (DED) is a multifactorial disease that is very often chronic. Various epidemiological studies carried out in the general population have shown that DED is a common disease, with a prevalence that varies between 5\% and 50\% depending on the criteria used to define DED, the population studied, and the geographic area analyzed. ${ }^{1-8}$ Studies in which the diagnosis was based primarily on signs generally found higher and more variable rates of DED, up to $75 \%$ in certain populations. ${ }^{8}$ In a study conducted in the USA, it was estimated that DED affects more than 3.2 million women aged $\geq 50$ years. ${ }^{9}$ In Spain, a study conducted in the northwest region of the country ${ }^{4}$ found that the prevalence of DED was $11 \%$, was more common in women than in men, and the prevalence was significantly related to aging. ${ }^{4}$

The definition of DED has evolved over time. In 2007, the Dry Eye WorkShop (DEWS) defined it as: "A multifactorial disease of the tears and ocular surface that results in symptoms of discomfort, visual disturbance, and tear film instability with potential damage to the ocular surface. It is accompanied by increased osmolarity of the tear film and inflammation of the ocular surface." 10 
In the latest update published in the year $2017,{ }^{11}$ the DEWS II defines it as a "multifactorial disease of the ocular surface characterized by a loss of homeostasis of the tear film, and accompanied by ocular symptoms, in which tear film instability and hyperosmolarity, ocular surface inflammation and damage, and neurosensory abnormalities play etiological roles."

DED was traditionally related to a reduced volume of tears. We could say that, currently, it is believed that dry eye involves a loss of the ability to maintain the equilibrium of tear components. ${ }^{12}$

Lacrimal dysfunction occurs when the lacrimal functional unit (LFU) consisting of the lacrimal glands (the main and accessory lacrimal glands, goblet cells, and meibomian glands) and its immunological and neuroendocrine components are not able to maintain a stable tear film. ${ }^{12}$

Alterations of the tear film are a consequence of damage to or dysfunction of one or more components of the LFU.

The etiology of the LFU alterations has been associated with multiple causes, environmental, genetic, infectious factors, etc, that may result in triggering of an acute inflammatory process that leads to DED. ${ }^{12-14}$

Any alteration of the LFU that involves less tear secretion or greater evaporation from the tear film will cause an increase in the hyperosmolarity of the tear film, which causes inflammation and alteration of the ocular surface. Among these alterations is deterioration of the mucin component of the tear and of the goblet cells. All these changes give rise to greater instability of the tear film, thus closing this vicious circle, and the disease tends to worsen if not treated adequately. ${ }^{15}$

Tear film hyperosmolarity has been considered as one of the central events in the physiopathology of DED. ${ }^{15}$ Instability of the tear film, produced either by a decrease in production, slow elimination, or inadequate composition of the tear, may lead to the osmolarity of the tear exceeding that of the epithelial cell. This induces the exit of water from the cell, resulting in a reduction of cell volume and an increase in the intracellular concentration of solutes, potentially damaging cellular metabolic functions. ${ }^{16,17}$ Tear hyperosmolarity leads to apoptotic processes and the release of proinflammatory factors, which in turn cause damage to the ocular surface, with a decrease of goblet cells and loss of corneal epithelial barrier function. ${ }^{18}$

DED can have a significant negative impact on quality of life, primarily due to irritation, chronic pain, ${ }^{19}$ and greater difficulty performing daily activities such as driving and reading. 9,20,21 These effects may also directly affect work productivity, provoking anxiety and/or depression. ${ }^{22}$
Given the chronic nature of this disease and the repercussions it may have on the quality of life, it is necessary that patients, health professionals, doctors, and pharmacists be aware that this disease must be treated adequately from the beginning.

DED can appear or worsen after cataract surgery. There are many causes, including severance of corneal nerve endings, inflammation, loss of goblet cells, and dysfunction of the meibomian glands. ${ }^{23}$ The incidence of DED after cataract surgery is around $10 \% .^{24}$

In relation to refractive surgery, it is estimated that between $20 \%$ and $55 \%$ of patients present persistent ocular symptoms, mostly described as dryness, burning, and discomfort, up to 6 months after refractive surgery using laser-assisted in-situ keratomileusis (LASIK). ${ }^{25}$

The aim of DED treatment should be to reestablish homeostasis of the ocular surface, to reduce signs and symptoms of the disease, and ultimately to improve the quality of life of patients.

Artificial tears are habitually used as the first therapeutic option for the treatment of DED in any stage of severity and, when necessary, in combination with other treatments. ${ }^{26,27}$

Artificial tears can contain different polymers, either isolated or in combination, along with other compounds such as electrolytes, vitamins, osmoprotectants, and lipids. Selection of the type should be adjusted to the characteristics of the patient and to the severity of dry eye from which the patient suffers, trying to replace the components altered by the DED. ${ }^{27}$

The objective of this article is to review the properties of the fixed combination formulation of carmellose (carboxymethyl cellulose [CMC]), hyaluronic acid (HA), and osmoprotectants (Optava Fusion ${ }^{\circledR}$; Allergan, Inc., Irvine, $\mathrm{CA}$ ), as well as to understand its action on the mechanisms that contribute to perpetuating the vicious circle of DED. Furthermore, this review also includes some considerations and recommendations on the use of artificial tears for better therapeutic management of DED.

\section{Hyaluronic acid}

HA is a naturally occurring high-molecular-weight polysaccharide made up of repeating disaccharide units of $\beta 1,3-\mathrm{N}$ acetylglucosamine and $\beta$ 1,4-glucuronic acid. ${ }^{28} \mathrm{HA}$ exists naturally in various human tissues, such as the umbilical cord, vitreous humor, dermis, and epidermis. ${ }^{29}$ The highest quantities of HA found in the human body are in the extracellular matrix of soft connective tissues. ${ }^{30}$

$\mathrm{HA}$ is the main component of the endothelial glycocalyx and is involved in cell transport. ${ }^{31}$ The specific physicochemical 
properties of HA give it a unique capacity for hydration, and it has been shown that in the renal medulla, where the HA content is very high, it can rapidly change depending on body hydration status. ${ }^{32}$ In summary, the kidney, which regulates fluid balance, uses HA dynamically to regulate the body's homeostasis. ${ }^{32}$

For pharmaceutical products, HA can be extracted from cockscomb or it can be synthesized from attenuated streptococcus strains through a fermentation process. ${ }^{33,34}$ Recently, a new industrial process for HA production using Bacillus subtilis has been developed. ${ }^{35,36}$ Both HA extracted from cockscomb and HA originating from fermentation of attenuated streptococcus strains are of high molecular weight $(>1 \mathrm{MDa})$, while HA produced from Bacillus subtilis is of medium molecular weight (0.6-1.0 MDa). ${ }^{37}$

Regardless of how the HA is obtained, there is more and more evidence that high-molecular-weight HA presents more benefits for the ocular surface than low-molecular-weight HA. ${ }^{38-42}$ The pharmaceutical industry manufactures various types of HA, with those of high molecular weight being more expensive to manufacture. ${ }^{37}$ This greater cost is due in part to higher molecular weight implying slower sterile filtration, which raises the price of the product. ${ }^{37}$

In ophthalmology, HA is used widely as a viscoelastic substance for use in intraocular surgeries, primarily in cataract surgery. ${ }^{43} \mathrm{HA}$ is also widely used for its viscoelastic and hydrating properties and its excellent biocompatibility in multiple types of artificial tears. ${ }^{44}$

The physicochemical characteristics of HA depend in part on its molecular weight and on the interactions with specific binding proteins called hyaladherins. ${ }^{30} \mathrm{HA}$ binds to the CD44 receptors present in the majority of cells on the ocular surface. ${ }^{45}$

One of the main characteristics of HA is its great hygroscopic capacity that allows retention of an amount of water up to 1,000 times its own weight. ${ }^{29,37}$

Another important characteristic is its mucoadhesiveness, through which it provides effective coating and lasting protection for the ocular surface. ${ }^{46,47}$

The viscosity of an ophthalmic formula is an essential parameter because it influences the efficacy of the formula, as this provides its ability to lubricate.

Therefore, a highly viscous solution has a higher ocular residence time and better contact of the product with the cornea and other ocular structures. ${ }^{37}$ On the other hand, a solution that is too viscous may cause blurred vision and be uncomfortable for the patient. The viscosity of HA formulas depends on the molecular weight and concentration of HA that they contain. The greater the molecular weight and concentration of the HA, the greater is the viscosity. ${ }^{37}$ Molecular weight is the sum of the atomic weights of the elements that constitute the molecule, so it is determined by its length: the greater the length, the greater is the molecular weight.

HA is pseudoplastic, with non-Newtonian rheological characteristics. ${ }^{28,29}$ Therefore, its viscosity varies as a function of the shear force exerted on it. ${ }^{28,29} \mathrm{HA}$ is viscous in order to adhere itself, but its resistance diminishes under the friction of blinking. ${ }^{38,48}$

It is desirable for the HA present in artificial tears to be of high molecular weight. In the HAs used as artificial tear polymers, the average molecular weight varies between 0.4 and 2.3 MDa. ${ }^{48}$ Under physiological conditions, highmolecular-weight HA contributes to the maintenance of tissue homeostasis. ${ }^{38}$

Various studies have found that high-molecular-weight HA protects corneal epithelial cells against different types of damage, such as ultraviolet solar radiation, ${ }^{39}$ preservatives present in ophthalmic solutions such as benzalkonium chloride (BAK), ${ }^{39}$ and irritants found in shampoos and other personal hygiene products. ${ }^{40}$

High-molecular-weight HA has a reparative effect on the ocular surface, stimulating epithelial migration ${ }^{41,42}$ and inhibiting the expression of proinflammatory mediators such as interleukin (IL)-6 and IL-8. ${ }^{38}$ In comparison, low-molecularweight HA seems to be involved in various processes related to healing, such as epidermal cell proliferation and activation of the angiogenic mechanisms of endothelial cells. ${ }^{38,49}$ Furthermore, different studies define low-molecular-weight $\mathrm{HA}$ as an active proinflammatory molecule that stimulates different immune cells (monocytes and macrophages), causing an increase in cytokines and chemokines and an increase in the expression of inducible nitric oxide synthase, which induces the production of metalloproteinases (MMPs), activation of the plasminogen $\mathrm{A}$ inhibitor, and inhibition of urokinase activity. ${ }^{38,49,50}$

In particular, low-molecular-weight HA $(\sim 200 \mathrm{kDa})$ can induce the expression of proinflammatory genes, such as the macrophage inflammatory protein macrophage chemotactic protein-1, as well as IL-2, IL-8, and tumor necrosis factor alpha. ${ }^{45}$ Low-molecular-weight fragments, resulting from the degradation of longer chains, may cause a proinflammatory effect instead of the desired effect. ${ }^{51}$

\section{Carmellose/carboxymethyl cellulose/CMC} Carmellose or CMC is a high-molecular-weight polysaccharide derived from natural cellulose obtained through chemical modification. $\mathrm{CMC}$ is one of the viscous polymers 
used most often in artificial tears to prolong their permanence on the ocular surface.

CMC binds directly to corneal epithelial cells for several hours through interactions between glucopyranose subunits and the glucose transporter. ${ }^{52}$ In addition, its binding to matrix proteins stimulates the migration of epithelial cells, which contributes to the reepithelialization and healing of corneal wounds. ${ }^{52,53}$

CMC improves the stability of the tear film in patients undergoing cataract surgery. ${ }^{54}$ Evidence also shows that CMC not only reduces the incidence of epithelial defects during refractive surgery with $\mathrm{LASIK},{ }^{55}$ but also facilitates the recovery of epithelial defects and reduces their symptoms. ${ }^{56}$ It is believed that this protective effect of CMC is directly related to its mucoadhesive properties. ${ }^{55,56}$

\section{Osmoprotectants}

One way of counteracting the effects of hyperosmolarity is based on the use of osmoprotectant substances, which are compatible solutes with the osmotic capacity to attract water that penetrate the cell and allow the volume and physiological functions of the epithelium to be reestablished. Compatible solutes are small soluble organic molecules without a charge that do not affect cell function. The osmoprotectant effect of these substances will depend, in great part, on the amount of the substance that the epithelial cell can capture and the amount of time that it can preserve that substance. Different osmoprotectants have different kinetics of cell entry and exit, have different speed of action, and can also act upon different processes. ${ }^{15}$ Thus, the simultaneous addition of various osmoprotectants can have a protective synergic effect against hyperosmolarity and a greater effect than the addition of only one. ${ }^{15}$

Different studies have shown the beneficial effect of osmoprotectants on the treatment of the DED. The results of an in vitro study showed that the osmoprotectants L-carnitine and erythritol can protect cultured human corneal epithelial cells from hyperosmolar conditions by lowering levels of mitogen-activated protein kinases. ${ }^{57}$ Additionally, the osmoprotectants also showed inflammatory-suppressing properties under hyperosmotic stress. ${ }^{58} \mathrm{~A}$ dry eye mouse study showed that osmoprotectants can reduce corneal staining, decrease cell apoptosis and inflammatory cytokines, and increase the number of goblet cells. ${ }^{59}$

The fixed combination as tear substitute has been formulated by combining $\mathrm{HA}$ and $\mathrm{CMC}$ with the following osmoprotectants: erythritol, glycerol, and also L-carnitine in the formula.

\section{Erythritol}

Erythritol, a four-carbon polyol, is a biological sweetener with applications in the food and pharmaceutical industries. It is small enough in size to penetrate the corneal epithelium through the aquaporins, which are water channels present in the cell membrane. ${ }^{60}$

Erythritol stabilizes proteins, reduces mitogen-activated protein kinase signals, ${ }^{57}$ and has a positive effect on the functionality of corneal epithelial cells undergoing hyperosmotic stress. ${ }^{16}$ Erythritol also inhibits the expression of MMP-9, MMP-2, and MMP-7 in corneal epithelial cells undergoing hyperosmotic stress. ${ }^{61}$

\section{L-Carnitine}

L-Carnitine (gamma-trimethyl-beta-hydroxy-butyrobetaine) is an amino acid found in foods and synthesized in the liver. It is a small molecule with a wide presence in all cells, from prokaryotes to eukaryotes. ${ }^{62}$ Its penetration of the cell depends on transporters located in the cell membrane (Organic cation transporter-1 [OCTN1], sodium dependent, and OCTN2). ${ }^{63}$ Study of the expression and location of organic cation transporters in the corneal and conjunctival epithelium suggests that L-carnitine may not only serve as an osmoprotectant agent in DED, but may also play a significant role in protecting against oxidative stress damage of corneal epithelial cells. ${ }^{63-65}$

L-Carnitine significantly suppresses the production of reactive oxygen species, and at the same time, it reduces oxidative damage in the cell membrane, modification of intracellular proteins, and oxidative damage to DNA. ${ }^{65}$ It also suppresses the production of the heme oxygenase- 1 and cyclooxygenase- 2 proteins, which protects the corneal epithelial cells from oxidative stress and also serves as a protective mechanism for the epithelial cells against the inflammatory response to hyperosmotic stress. ${ }^{65}$ Hyperosmolarity interrupts the antioxidant defense system by reducing the production of antioxidant enzymes such as superoxide dismutase and glutathione peroxidase, among others. However, L-carnitine can restore the levels of these antioxidant enzymes. ${ }^{65}$

\section{Glycerol}

Glycerol, a polyalcohol with three hydroxyl groups, is an important intermediary in the metabolism of both prokaryotic and eukaryotic cells. It has been used for a long time in various therapeutic and industrial processes. It can penetrate epithelial cell membranes through aquaglyceroporins. ${ }^{52}$

It has been shown to have an osmoprotectant effect on corneal epithelial cells. ${ }^{60}$ Glycerol can play an important 
role as a short half-life osmoprotectant, and its results can improve if combined with a long half-life osmoprotectant such as L-carnitine. ${ }^{15}$

\section{Combination of hyaluronic acid, carboxymethyl cellulose, and osmoprotectants: current scientific evidence}

Artificial tears are among the recommended measures for the first step of treatment for DED. ${ }^{26,27}$ Figure 1 illustrates the different components of the fixed combination formulated of HA, CMC, and osmoprotectants and their interaction with the ocular surface cells.

The combination of CMC, HA, and osmoprotectants has shown its efficacy in experimental studies. ${ }^{66}$ In one of these studies, conducted in animals in which dry eye was induced using a controlled environmental system, the efficacy of a new artificial tear formula composed of $0.5 \% \mathrm{CMC}+0.1 \%$ $\mathrm{HA}+$ osmoprotectants was evaluated. ${ }^{67}$ The results of this study showed that this fixed combination was superior to products that contained only CMC or HA separately, in its capacity to reduce corneal alterations or the loss of goblet cells. ${ }^{67}$

The efficacy and safety of the combination of HA, CMC, and osmoprotectants have been shown in various clinical trials. In a 3-month multicenter, double-blind, prospective study that included 305 patients with dry eye, the efficacy and safety of two formulas that contained $0.5 \% \mathrm{CMC}$ and $\mathrm{HA}$ at two concentrations $(0.10 \%$ and $0.15 \%$, respectively), and osmoprotectants were compared with a standard CMC formula, in patients with DED. ${ }^{68}$ The patients were randomized in a 1:1:1 ratio to receive treatment with $0.5 \% \mathrm{CMC}+0.10 \%$ $\mathrm{HA}$, and osmoprotectants, $0.5 \% \mathrm{CMC}+0.15 \% \mathrm{HA}$ (CHO-2), and osmoprotectants, or the standard CMC formula. ${ }^{68}$ The results of this study showed that the treatment with $0.5 \% \mathrm{CMC}+0.10 \% \mathrm{HA}$ and osmoprotectants significantly reduced the symptoms of DED in comparison to both $\mathrm{CHO}-2$ and $\mathrm{CMC} .{ }^{68}$ In conclusion, the combination of $\mathrm{CMC}$ and $0.10 \% \mathrm{HA}$, in an osmoprotectant formula, provides a beneficial option for the treatment of dry eye. ${ }^{68}$

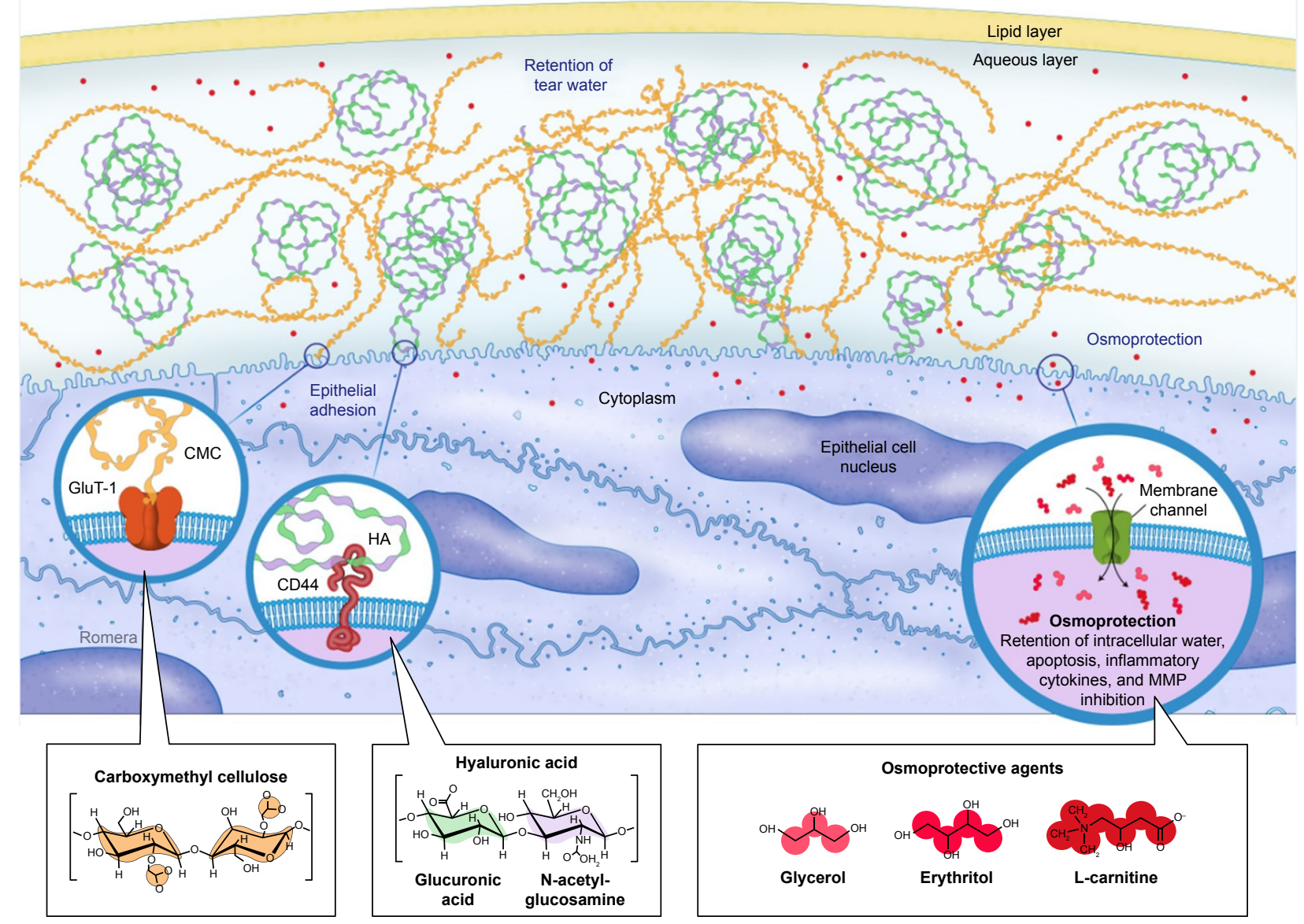

Figure I Mechanism of action of the different components of the fixed combined formulation of HA, CMC, and osmoprotectants (Optava Fusion ${ }^{\circledR}$; Allergan, Inc., Irvine, CA, USA).

Abbreviations: CMC, carboxymethyl cellulose; HA, hyaluronic acid; MMP, matrix metalloproteinases. 
This study highlights that the formula containing $0.10 \%$ HA showed better results in terms of ocular symptoms than the formula with $0.15 \% \mathrm{HA}$. The patients in the group treated with the $0.15 \%$ HA formula reported greater visual disturbance, while the data related to drop thickness and blurred vision immediately after application were more favorable with the $0.5 \% \mathrm{CMC}+0.10 \% \mathrm{HA}$, and osmoprotectants formulation. ${ }^{68}$

Furthermore, this combination has also been shown to be effective for improving the signs and symptoms of dry eye in patients who undergo cataract surgery ${ }^{69}$ A prospective study in a group of 282 patients evaluated the efficacy and safety of an artificial tear formula that contained $0.5 \%$ $\mathrm{CMC}+0.10 \% \mathrm{HA}$ for the treatment of ocular discomfort and stability of the tear film in the eyes after cataract surgery. ${ }^{69}$ According to the results of this study, in comparison with the control group treated with a steroid and a topical antibiotic, the combination of $0.10 \% \mathrm{HA}$ and $0.5 \% \mathrm{CMC}$ was effective and well tolerated for reducing the symptoms of DED after cataract surgery. ${ }^{69}$

Recently, in a randomized, investigator-blinded prospective study, the efficacy and safety of the combination of osmoprotectants/CMC/HA were evaluated in terms of the reduction of symptoms in patients with moderate-to-severe DED, in comparison with a compound with $0.18 \% \mathrm{HA}^{70}$ The results of this study showed that, with regard to the improvement of DED symptoms, the combined formulation of $\mathrm{HA} / \mathrm{CMC} /$ osmoprotectants was not inferior to $0.18 \%$ HA. Also, compared with $0.18 \%$ HA, a higher percentage of patients reported a significantly lower amount of severe itching/burning, foreign body sensation (grittiness), and ocular pain/irritation after 3 months of treatment with the combination of osmoprotectants/CMC/HA. ${ }^{70}$ Furthermore, a lower number of patients presented ocular pain/irritation on day 35 of treatment in the group treated with the combination of osmoprotectants/CMC/HA in comparison with HA. ${ }^{70}$

In studies in real practice, the combination of $\mathrm{HA}, \mathrm{CMC}$, and osmoprotectants has been shown to improve the ocular surface and the stability of the tear film, thus enabling a reduction of the hyperosmolarity of the tear film, ${ }^{71}$ which is one of the main etiopathogenic elements associated with DED.

The physicochemical properties of the $0.1 \% \mathrm{HA} / 0.5 \%$ $\mathrm{CMC}$ and osmoprotectants combination have been analyzed along with other artificial tear substitutes that contain HA. It was verified that the fixed combination formulation mentioned contains high-molecular-weight HA $(1,178 \mathrm{KDa})$, which is desirable for the previously mentioned protective effect. In addition, this HA has a low polydispersity index (PDI =1.1). Having a low PDI is a prerequisite of the polymers included in pharmaceutical products and is related to the quality of the raw material ${ }^{72}$ and the ocular retention time. ${ }^{73}$

The complete tear film with mucin-aqueous and lipid components has pseudoplastic, positive thixotropic, nonNewtonian fluid behavior. ${ }^{74}$ The pseudoplasticity or viscoelasticity explains the variability in viscosity under a specific sliding force, and positive thixotropy refers to recovery of the initial viscosity over time.

The combination of two viscoelastic polymers such as $\mathrm{CMC}$ and HA provides some rheological characteristics that are suitable for the formulation of an artificial tear, in terms of the required pseudoplasticity and thixotropy that are similar to natural tears.

In this sense, it was verified that the fixed combined formulation has an appropriate viscosity $(\sim 20 \mathrm{cP})$ and viscoelasticity that allow it to adapt to blinking. Viscosity is related to ocular residence time and potential clinical benefits, with it typically being preferable to have a viscosity $>10 \mathrm{cP}$. In this case, this product has a good viscosity, remaining below the limit from which a greater number of patients may begin to report blurred vision. ${ }^{72,73}$

Lastly, this analysis showed that, among the products analyzed that contained a high-molecular-weight HA $(>1 \mathrm{MDa}$ ), the fixed combined formulation is the one that has the lowest sodium concentration. This is also desirable because an excess of salts in the tear film is associated with inflammatory processes, ocular surface damage, and symptoms of discomfort. In this case, the product's osmolarity is achieved due to the inclusion of compatible solutes (osmoprotectants) instead of electrolytes. ${ }^{72}$

It has been shown that $\mathrm{CMC}$ is a polymer that provides greater molecular stability to other polysaccharide polymers and proteins, which may benefit its combination with osmoprotectant molecules. ${ }^{75,76}$

In addition, due to the reported physicochemical properties of CMC, as well as its rheological behavior, hydrogel formulas can be obtained with properties suitable for stabilization and controlled release of other molecules incorporated therein. ${ }^{77}$

\section{Considerations for the use of artificial tears}

DED is often chronic, and therefore, tends to require lifelong treatment. In those patients who suffer consequences of environmental circumstances that predispose them to suffering symptoms of dry eye temporarily (eg, due to exposure to air 
conditioning or ventilation systems and working in front of a computer), treatment with artificial tear substitutes may be required..$^{27}$ On the other hand, once the disease has been established, treatment must be continued even when there is an observed improvement in the signs and symptoms of the disease. Lack of treatment compliance may lead to progression of the signs and symptoms of the disease, resulting in social and even workplace impact on the patient. ${ }^{27}$

The DEWS includes environmental changes and artificial tear substitutes, among others, as the first line of treatment. ${ }^{10,78}$ Environmental changes should be aimed at reducing exposure of the ocular surface to air currents, increasing environmental humidity, and working with computer screens that are not in a highly elevated position. ${ }^{10,78}$

In terms of treatment with artificial tear substitutes, in general, it is recommended to follow a fixed treatment regimen that adapts the number of instillations/day according to the severity of the pathology. In this sense, milder cases may need multiple instillations per day, which may be reinforced in cases of exposure to dry environments, air conditioners, or other conditions that worsen the symptoms of dry eye. On the other hand, severe cases may require a greater number of instillations per day and should be accompanied by the appropriate environmental changes and prescribed concomitant treatments. ${ }^{10,27,78}$

There are currently numerous artificial tears formulations available. However, not all of them have the same capacity for hydration, lubrication, and osmoprotection as needed for adequate management of the disease. ${ }^{78}$ It must be kept in mind that it is important for the treatment to be effective from the start to prevent the disease from progressing. In addition to environmental measures and the use of artificial tears (preferably without preservatives), the addition of other therapeutic "weapons" may be required as the patient's degree of severity increases, depending on their availability, the experience of the doctor, and the etiology of the dry eye. ${ }^{78}$ In order to establish comprehensive treatment for more severe cases, different measures will be necessary to control the existing inflammatory state (corticosteroids, cyclosporine, etc), reparation or regeneration of the affected tissues on the ocular surface (blood derivatives, cell therapies, etc), as well as other measures that meet the needs of the type of dry eye that is being treated (tear duct plugs, eyelid heating, lipids, surgeries, etc). ${ }^{78}$

Specialists indicate the product and regimen that they believe is most suitable for each patient. However, in view of the wide range of products that are seemingly similar, it is possible that at some point the patient or pharmacist will decide to change the prescription, ignoring the injury that the patient may suffer.

Therefore, it is very important that the information is adapted and personalized in each case so that the patient understands the scope of his or her disease, as well as the therapeutic strategy suggested.

\section{Final conclusions}

DED is an often chronic disease that tends to need prolonged treatment. It is a highly prevalent pathology that may have a very significant effect on the ability to perform daily tasks, and therefore, it requires adequate treatment from the early stages of the disease. The combination of HA, CMC, and osmoprotectants has proven to be effective in the treatment of the signs and symptoms of dry eye through the synergic action of all its components. Therefore, it can be a recommended option for dry eye of any degree of severity. Overall, artificial tear substitutes are a therapeutic option that can be used from mild cases to the most severe cases in combination with other treatments and multidisciplinary recommendations, which may include hygienic, nutritional, psychological, and lifestyle measures and how to adjust environmental conditions.

\section{Acknowledgments}

The writing of the document and editorial support were provided to the authors by Ciencia y Deporte SL and Manuel Romera (www.ilustracionmedica.es). Funding for meeting logistics, editorial assistance, and publication fees was provided by Allergan SA. This article was produced at the request of the investigators following a round table discussion held with all authors on December 15, 2016, in Madrid, Spain. The article represents a consensus of the opinions that the authors reached at these meetings. No payment was received for authoring this document.

\section{Author contributions}

All authors were involved in the entire process, from the design to the critical review of the manuscript, and they maintained complete control over the direction and content of the document.

\section{Disclosure}

The authors report no conflicts of interest in this work.

\section{References}

1. Bjerrum KB. Keratoconjunctivitis sicca and primary Sjögren's syndrome in a Danish population aged 30-60 years. Acta Ophthalmol Scand. 1997;75(3):281-286. 
2. McCarty CA, Bansal AK, Livingston PM, Stanislavsky YL, Taylor HR. The epidemiology of dry eye in Melbourne, Australia. Ophthalmology. 1998;105(6):1114-1119.

3. Versura P, Cellini M, Torreggiani A, Profazio V, Bernabini B, Caramazza R. Dryness symptoms, diagnostic protocol and therapeutic management: a report on 1,200 patients. Ophthalmic Res. 2001;33(4): 221-227.

4. Viso E, Rodriguez-Ares MT, Gude F. Prevalence of and associated factors for dry eye in a Spanish adult population (the Salnes Eye Study). Ophthalmic Epidemiol. 2009;16(1):15-21.

5. Young G, Chalmers RL, Napier L, Hunt C, Kern J. Characterizing contact lens-related dryness symptoms in a cross-section of UK soft lens wearers. Cont Lens Anterior Eye. 2011;34(2):64-70.

6. Reitmeir P, Linkohr B, Heier M, et al. Common eye diseases in older adults of southern Germany: results from the KORA-Age study. Age Ageing. 2017;46(3):481-486.

7. Osae AE, Gehlsen U, Horstmann J, et al. Epidemiology of dry eye disease in Africa: the sparse information, gaps and opportunities. Ocul Surf. 2017;15(2):159-168.

8. Stapleton F, Alves M, Bunya VY, et al. TFOS DEWS II epidemiology report. Ocul Surf. 2017;15(3):334-365.

9. Schaumberg DA, Sullivan DA, Buring JE, Dana MR. Prevalence of dry eye syndrome among US women. Am J Ophthalmol. 2003;136(2): 318-326.

10. 2007 Report of the International Dry Eye WorkShop (DEWS). Ocul Surf. 2007;5:1-204.

11. Craig JP, Nichols KK, Akpek EK, et al. TFOS DEWS II definition and classification report. Ocul Surf. 2017;15(3):276-283.

12. Stern ME, Gao J, Siemasko KF, Beuerman RW, Pflugfelder SC. The role of the lacrimal functional unit in the pathophysiology of dry eye. Exp Eye Res. 2004;78(3):409-416.

13. Enríquez-de-Salamanca A, Bonini S, Calonge M. Molecular and cellular biomarkers in dry eye disease and ocular allergy. Curr Opin Allergy Clin Immunol. 2012;12(5):523-533.

14. Calonge M, Enríquez-de-Salamanca A, Diebold Y, et al. Dry eye disease as an inflammatory disorder. Ocul Immunol Inflamm. 2010; 18(4):244-253.

15. Baudouin C, Aragona P, Messmer EM, et al. Role of hyperosmolarity in the pathogenesis and management of dry eye disease: proceedings of the OCEAN group meeting. Ocul Surf. 2013;11(4):246-258.

16. Clouzeau C, Godefroy D, Riancho L, Rostène W, Baudouin C, Brignole-Baudouin F. Hyperosmolarity potentiates toxic effects of benzalkonium chloride on conjunctival epithelial cells in vitro. Mol Vis. 2012;18:851-863.

17. Bron AJ, Yokoi N, Gafney E, Tiffany JM. Predicted phenotypes of dry eye: proposed consequences of its natural history. Ocul Surf. 2009; 7(2):78-92.

18. Ubels JL, Williams KK, Lopez Bernal D, Edelhauser HF. Evaluation of effects of a physiologic artificial tear on the corneal epithelial barrier: electrical resistance and carboxy fluorescein permeability. $A d v \operatorname{Exp}$ Med Biol. 1994;350:441-452.

19. Nichols KK. Patient-reported symptoms in dry dye disease. Ocul Surf. 2006; 4:137-145.

20. Miljanović B, Dana R, Sullivan DA, Schaumberg DA. Impact of dry eye syndrome on vision-related quality of life. Am J Ophthalmol. 2007;143(3):409-415.

21. Le Q, Zhou X, Ge L, Wu L, Hong J, Xu J. Impact of dry eye syndrome on vision-related quality of life in a non-clinic-based general population. BMC Ophthalmol. 2012;12:22.

22. Li M, Gong L, Sun X, Chapin WJ. Anxiety and depression in patients with dry eye syndrome. Curr Eye Res. 2011;36(1):1-7.

23. Sutu C, Fukuoka H, Afshari NA. Mechanisms and management of dry eye in cataract surgery patients. Curr Opin Ophthalmol. 2016; 27(1):24-30.

24. Kasetsuwan N, Satitpitakul V, Changul T, Jariyakosol S. Incidence and pattern of dry eye after cataract surgery. PLoS One. 2013;8(11):e78657.
25. Levitt AE, Galor A, Weiss JS, et al. Chronic dry eye symptoms after LASIK: parallels and lessons to be learned from other persistent postoperative pain disorders. Mol Pain. 2015;11:21.

26. Behrens A, Doyle JJ, Stern L, et al. Dysfunctional tear syndrome study group. Dysfunctional tear syndrome: a Delphi approach to treatment recommendations. Cornea. 2006;25(8):900-907.

27. Mateo Orobia AJ, Benítez del Castillo JM, Calonge M, et al. Protocolo de prácticaclínicapreferente: Enfermedad de ojoseco. Adaptación del original: dry eye syndrome; 2013. Available from: https://www.aao. org/preferred-practice-pattern/dry-eye-syndrome-ppp--2013. Accessed November 21, 2017.

28. Goa KL, Benfield P. Hyaluronic acid. A review of its pharmacology and use as a surgical aid in ophthalmology, and its therapeutic potential in joint disease and wound healing. Drugs. 1994;47(3):536-566.

29. Kogan G, Soltés L, Stern R, Gemeiner P. Hyaluronic acid: a natural biopolymer with a broad range of biomedical and industrial applications. Biotechnol Lett. 2007;29(1):17-25.

30. Iannitti T, Lodi D, Palmieri B. Intra-articular injections for the treatment of osteoarthritis: focus on the clinical use of hyaluronic acid. Drugs R D. 2011;11(1):13-27.

31. Dane MJ, van den Berg BM, Lee DH, et al. A microscopic view on the renal endothelial glycocalyx. Am J Physiol Renal Physiol. 2015; 308(9):F956-F966.

32. Stridh S, Palm F, Hansell P. Renal interstitial hyaluronan: functional aspects during normal and pathological conditions. Am J Physiol Regul Integr Comp Physiol. 2012;302(11):R1235-R1249.

33. Chong BF, Blank LM, Mclaughlin R, Nielsen LK. Microbial hyaluronic acid production. Appl Microbiol Biotechnol. 2005;66(4):341-351.

34. Balazs EA. Ultra-pure, high molecular wt. Hyaluronic acid- is nonantigenic and used as synthetic aq. Humour and synovial fluid, as nerve tissue and wound protector and drug carrier. United States patent US 4141973; 1979 Feb 27.

35. Widner B, Behr R, Von Dollen S, et al. Hyaluronic acid production in Bacillus subtilis. Appl Environ Microbiol. 2005;71(7):3747-3752.

36. Jin P, Kang Z, Yuan P, Du G, Chen J. Production of specific-molecularweight hyaluronan by metabolically engineered Bacillus subtilis 168 . Metab Eng. 2016;35:21-30.

37. Guillaumie F, Furrer P, Felt-Baeyens O, et al. Comparative studies of various hyaluronic acids produced by microbial fermentation for potential topical ophthalmic applications. J Biomed Mater Res A. 2010; 92(4):1421-1430.

38. Jiang D, Liang J, Noble PW. Hyaluronan in tissue injury and repair. Annu Rev Cell Dev Biol. 2007;23:435-461.

39. Pauloin T, Dutot M, Joly F, Warnet JM, Rat P. High molecular weight hyaluronan decreases UVB-induced apoptosis and inflammation in human epithelial corneal cells. Mol Vis. 2009;15:577-583.

40. Pauloin T, Dutot M, Liang H, Chavinier E, Warnet JM, Rat P. Corneal protection with high-molecular-weight hyaluronan against in vitro and in vivo sodium lauryl sulfate-induced toxic effects. Cornea. 2009; 28(9):1032-1041.

41. Wu $\mathrm{H}$, Zhang $\mathrm{H}$, Wang $\mathrm{C}$, et al. Genoprotective effect of hyaluronic acid against benzalkonium chloride-induced DNA damage in human corneal epithelial cells. Mol Vis. 2011;17:3364-3370.

42. Wu CL, Chou HC, Li JM, et al. Hyaluronic acid-dependent protection against alkali-burned human corneal cells. Electrophoresis. 2013; 34(3):388-396.

43. Balazs EA. Hyaluronan as an ophthalmic viscoelastic device. Curr Pharm Biotechnol. 2008;9(4):236-238.

44. Rah MJ. A review of hyaluronan and its ophthalmic applications. Optometry. 2011;82(1):38-43.

45. Misra S, Hascall VC, Markwald RR, Ghatak S. Interactions between Hyaluronan and Its Receptors (CD44, RHAMM) Regulate the Activities of Inflammation and Cancer. Front Immunol. 2015;6:201.

46. Saettone MF, Monti D, Torracca MT, Chetoni P. Mucoadhesive ophthalmic vehicles: evaluation of polymeric low-viscosity formulations. J Ocul Pharmacol. 1994;10:83-92. 
47. Greaves JL, Wilson CG. Treatment of diseases of the eye with mucoadhesive delivery systems. Adv Drug Delivery Rev. 1993;11:349-383.

48. Torras J, Alarcon S. Actualización en lágrimasartificiales. Ann Oftalmol. 2016;24(1):3-19.

49. Girish KS, Kemparaju K. The magic glue hyaluronan and its eraser hyaluronidase: a biological overview. Life Sci. 2007;80:1921-1943.

50. Stern R, Asari AA, Sugahara KN. Hyaluronan fragments: an information-rich system. Eur J Cell Biol. 2006;85:699-715.

51. Litwiniuk M, Krejner A, Speyrer MS, Gauto AR, Grzela T. Hyaluronic acid in inflammation and tissue regeneration. Wounds. 2016;28(3): 78-88.

52. Garrett Q, Simmons PA, Xu S, et al. Carboxymethyl cellulose binds to human corneal epithelial cells and is a modulator of corneal epithelial wound healing. Invest Ophthalmol Vis Sci. 2007;48(4):1559-1567.

53. Garrett Q, Xu S, Simmons PA, et al. Carboxymethyl cellulose stimulates rabbit corneal epithelial wound healing. Curr Eye Res. 2008;33(7): 567-573.

54. Yao K, Bao Y, Ye J, et al. Efficacy of $1 \%$ carboxymethyl cellulose sodium for treating dry eye after phacoemulsification: results from a multicenter, open-label, randomized, controlled study. BMC Ophthalmol. 2015;15:28.

55. Ahee JA, Kaufman SC, Samuel MA, Bogorad D, Wee C. Decreased incidence of epithelial defects during laser in situ keratomileusis using intraoperative nonpreserved carboxymethylcellulose sodium $0.5 \%$ solution. J Cataract Refract Surg. 2002;28:1651-1654.

56. Lenton LM, Albietz JM. Effect of carmellose base artificial tears on the ocular surface in eyes after laser in situ keratomileusis. J Refract Surg. 1999;15:S227-S231.

57. Corrales RM, Luo L, Chang EY, Pflugfelder SC. Effects of osmoprotectants on hyperosmolar stress in cultured human corneal epithelial cells. Cornea. 2008;27(5):574-579.

58. Hua X, Su Z, Deng R, Lin J, Li DQ, Pflugfelder SC. Effects of L-carnitine, erythritol and betaine on pro-inflammatory markers in primary human corneal epithelial cells exposed to hyperosmotic stress. Curr Eye Res. 2015;40(7):657-667.

59. Chen W, Zhang X, Li J, Wang Y, Chen Q, Hou C, Garrett Q. Efficacy of osmoprotectants on prevention and treatment of murine dry eye. Invest Ophthalmol Vis Sci. 2013;54(9):6287-6297.

60. Simmons PA, Chang-Lin JE, Chung Q, Vehige G, Welty D. Effect of compatible solutes on transepithelial electrical resistance and uptake in primary rabbit corneal epithelial cell layers model. ARVO. 2007;48(13).

61. Deng R, Su Z, Hua X, Zhang Z, Li DQ, Pflugfelder SC. Osmoprotectants suppress the production and activity of matrix metalloproteinases induced by hyperosmolarity in primary human corneal epithelial cells. Mol Vis. 2014;20:1243-1252.

62. Peluso G, Barbarisi A, Savica V, et al. Carnitine: an osmolyte that plays a metabolic role. J Cell Biochem. 2000;80(1):1-10.

63. Garrett Q, Xu S, Simmons PA, Vehige J, Flanagan JL, Willcox MD. Expression and localization of carnitine/organic cation transporter OCTN1 and OCTN2 in ocular epithelium. Invest Ophthalmol Vis Sci. 2008;49(11):4844-4849.

64. Xu S, Flanagan JL, Simmons PA, Vehige J, Willcox MD, Garrett Q. Transport of L-carnitine in human corneal and conjunctival epithelial cells. Mol Vis. 2010;16:1823-1831.

Clinical Ophthalmology

\section{Publish your work in this journal}

Clinical Ophthalmology is an international, peer-reviewed journal covering all subspecialties within ophthalmology. Key topics include: Optometry; Visual science; Pharmacology and drug therapy in eye diseases; Basic Sciences; Primary and Secondary eye care; Patient Safety and Quality of Care Improvements. This journal is indexed on Submit your manuscript here: http://www.dovepress.com/clinical-ophthalmology-journal
65. Hua X, Deng R, Li J, et al. Protective effects of L-Carnitine against oxidative injury by hyperosmolarity in human corneal epithelial cells. Invest Ophthalmol Vis Sci. 2015;56(9):5503-5511.

66. Simmons PA, Beard BJ, Vehige JG. Optimizing viscosity of ophthalmic solutions with the combination of two polymers. Presented at: the 7th International Conference on the Tear Film \& Ocular Surface: Basic Science and Clinical Relevance; September 18-21, 2013; Taormina, Italy.

67. She Y, Li J, Xiao B, et al. Evaluation of a novel artificial tear in the prevention and treatment of dry eye in an animal model. J Ocul Pharmacol Ther. 2015;31(9):525-530.

68. Simmons PA, Liu H, Carlisle-Wilcox C, Vehige JG. Efficacy and safety of two new formulations of artificial tears in subjects with dry eye disease: a 3-month, multicenter, active-controlled, randomized trial. Clin Ophthalmol. 2015;9:665-675.

69. Mencucci R, Boccalini C, Caputo R, Favuzza E. Effect of a hyaluronic acid and carboxymethyl cellulose ophthalmic solution on ocular comfort and tear-film instability after cataract surgery. J Cataract Refract Surg. 2015;41(8):1699-1704.

70. Labetoulle M, Chiambaretta F, Shirlaw A, Leaback R, Baudouin C. Osmoprotectants, carboxymethylcellulose and hyaluronic acid multiingredient eye drop: a randomized controlled trial in moderate to severe dry eye. Eye (Lond). 2017;31(10):1409-1416.

71. Mateo AJ, Del Prado E, Blasco A, et al. Role of a hyaluronic acid and carboxymethylcellulose ophthalmic solution on maintenance of tear film homeostasis in moderate to severe dry eye patients. Presented at: the international Symposium on Ocular Pharmacology \& Therapeutics (ISOPT); December 1-3; 2016; Rome. Available from: http:// www.isoptclinical.com/Events/Display/ISOPT2016?Page=Program. Accessed November 21, 2017.

72. Simmons P, Aragona P, Wang H, Wang T. Properties Of Hyaluronic Acid-Based Eye Drops. Presented at: the international Symposium on Ocular Pharmacology \& Therapeutics (ISOPT); December 1-3; 2016; Rome. Available from: http://www.isoptclinical.com/Events/Display/ ISOPT2016?Page=Program. Accessed November 21, 2017.

73. Simmons P, Aragona P, Wang H, Wang T. Physiochemical Properties Of Hyaluronic Acid-based Eye Drops. Presented at: the 8th International Conference on the Tear Film \& Ocular Surface (TFOS): Basic Science and Clinical Relevance; September 7-10; 2016; Montpellier, France.

74. Gouveia SM, Tiffany JM. Human tear viscosity: an interactive role for proteins and lipids. Biochim Biophys Acta. 2005;1753(2):155-163.

75. Zhang LM, Kong T. Aqueous polysaccharide blends based on hydroxypropyl guar gum and carboxymethyl cellulose: synergistic viscosity and thixotropic properties. Colloid Polym Sci. 2006;285(2):145-151.

76. Huan Y, Zhang S, Vardhanabhuti B. Influence of the molecular weight of carboxymethylcellulose on properties and stability of whey proteinstabilized oil-in-water emulsions. J Dairy Sci. 2016;99(5):3305-3315.

77. Ghica MV, Hîrjău M, Lupuleasa D, Dinu-Pîrvu CE. Flow and thixotropic parameters for rheological characterization of hydrogels. Molecules. 2016;21(6). pii: E786.

78. Jones L, Downie LE, Korb D, et al. TFOS DEWS II management and therapy report. Ocul Surf. 2017;15(3):575-628.

\section{Dovepress}

PubMed Central and CAS, and is the official journal of The Society of Clinical Ophthalmology (SCO). The manuscript management system is completely online and includes a very quick and fair peer-review system, which is all easy to use. Visit http://www.dovepress.com/ testimonials.php to read real quotes from published authors. 